\title{
How large are projected 21st century storm track changes?
}

Article

Published Version

Open Access (OnlineOpen)

Harvey, B. J., Shaffrey, L. C., Woollings, T. J., Zappa, G. and Hodges, K. I. (2012) How large are projected 21st century storm track changes? Geophysical Research Letters, 39 (18). L18707. ISSN 1944-8007 doi:

https://doi.org/10.1029/2012GL052873 Available at https://centaur.reading.ac.uk/33376/

It is advisable to refer to the publisher's version if you intend to cite from the work. See Guidance on citing.

Published version at: http://dx.doi.org/10.1029/2012GL052873

To link to this article DOI: http://dx.doi.org/10.1029/2012GL052873

Publisher: American Geophysical Union

All outputs in CentAUR are protected by Intellectual Property Rights law, including copyright law. Copyright and IPR is retained by the creators or other copyright holders. Terms and conditions for use of this material are defined in the End User Agreement.

\section{www.reading.ac.uk/centaur}

\section{CentAUR}

Central Archive at the University of Reading 
Reading's research outputs online 


\title{
How large are projected 21st century storm track changes?
}

\author{
B. J. Harvey, ${ }^{1}$ L. C. Shaffrey, ${ }^{1}$ T. J. Woollings, ${ }^{2}$ G. Zappa, ${ }^{1}$ and K. I. Hodges ${ }^{3}$ \\ Received 27 June 2012; revised 7 August 2012; accepted 8 August 2012; published 25 September 2012.
}

[1] Projected changes in the extra-tropical wintertime storm tracks are investigated using the multi-model ensembles from both the third and fifth phases of the World Climate Research Programme's Coupled Model Intercomparison Project (CMIP3 and CMIP5). The aim is to characterize the magnitude of the storm track responses relative to their present-day year-to-year variability. For the experiments considered, the 'middle-of-the-road' scenarios in each CMIP, there are regions of the Northern Hemisphere where the responses of up to $40 \%$ of the models exceed half of the inter-annual variability, and for the Southern Hemisphere there are regions where up to $60 \%$ of the model responses exceed half of the inter-annual variability. Citation: Harvey, B. J., L. C. Shaffrey, T. J. Woollings, G. Zappa, and K. I. Hodges (2012), How large are projected 21 st century storm track changes?, Geophys. Res. Lett., 39, L18707, doi:10.1029/2012GL052873.

\section{Introduction}

[2] The extratropical storm tracks are an important source of climate variability, and a component of the atmospheric circulation that has potential for large societal impacts if they change [Pinto et al., 2007; Dailey et al., 2009; Schwierz et al., 2010]. Many recent studies have made predictions as to how the storm tracks may change in the future, and there is now an emerging consensus on the qualitative nature of some of the larger scale features [e.g., Yin, 2005; Bengtsson and Hodges, 2006; Ulbrich et al., 2008, 2009; Catto et al., 2011]. Relatively little attention has been given, however, to interpreting the magnitude of the predicted changes with respect to typical present-day variations, an issue particularly pertinent to storm track statistics owing to the magnitude of their inter-annual and inter-decadal variations [Alexandersson et al., 1998; Wang et al., 2009; Cornes and Jones, 2011; Donat et al., 2011]. Several recent studies have however investigated the relative importance of local climate change responses relative to internal variability in a number of other atmospheric variables, most notably temperature [Mahlstein et al., 2011; Hawkins and Sutton, 2012] and precipitation [Mahlstein et al., 2012].

[3] This study addresses this issue for the extratropical storm tracks, as measured by the $2-6$ day bandpass filtered mean sea level pressure (MSLP) variance, by comparing the

\footnotetext{
${ }^{1}$ National Centre for Atmospheric Science, Department of Meteorology, University of Reading, Reading, UK.

${ }^{2}$ Department of Meteorology, University of Reading, Reading, UK.

${ }^{3}$ National Centre for Earth Observation, Environmental Systems Science Centre, University of Reading, Reading, UK.

Corresponding author: B. J. Harvey, Department of Meteorology, University of Reading, Earley Gate, PO Box 243, Reading RG6 6BB, UK. (b.j.harvey@reading.ac.uk)

(C2012. American Geophysical Union. All Rights Reserved. 0094-8276/12/2012GL052873
}

magnitude of the late 21 st century wintertime storm track responses in an ensemble of climate models with the magnitude of typical year-to-year variability. In particular, the response of each model's wintertime storm tracks are compared locally to a fraction of their inter-annual standard deviations in a simulation of the recent past. The value of 0.5 has been arbitrarily chosen as a suitable fraction for this study, meaning that a storm track response is considered to be large if it is of a similar order of magnitude to the present-day variability.

\section{Data and Methods}

[4] Three sources of data have been used in the analysis presented here: the multi-model datasets of phases three and five of the World Climate Research Programme's recent Coupled Model Intercomparison Project, CMIP3 [Meehl et al., 2007] and CMIP5 [Taylor et al., 2011] respectively, and the 56-member ensemble of the Twentieth Century Reanalysis Project (20CR) [Compo et al., 2011]. Two periods of data have been considered for each of the CMIP ensembles, one representing late 20th century conditions and one representing a 'middle-of-the-road' climate change scenario at the end of the 21st century; for CMIP3, years 1961-2000 from the 20C3M runs and years 2081-2100 from the SRESA1B runs, and for CMIP5, years 1976-2005 from the 20C runs and years 2070-2099 from the RCP4.5 runs. Only 19 of the CMIP3 models have the daily mean data required for the analysis, and at the time of writing only 19 of the CMIP5 models had data available. A complete list of the models used in this study is provided in the auxiliary material. ${ }^{1}$

[5] These two climate change scenarios (SRESA1B and RCP4.5) are not the same [see, e.g., Taylor et al., 2011], and this should be kept in mind throughout the analysis presented here. In addition, the models making up the two ensembles are different, with the CMIP5 models generally being more developed versions of those in CMIP3. As a guide for comparison between the ensembles, the multimodel mean global surface temperature change between the present day and future runs for the CMIP3 SRESA1B scenario (years 1961-2000 and 2081-2100 respectively) is about $2.8 \mathrm{~K}$, whereas that of the CMIP5 RCP4.5 scenario (years 1976-2005 and 2070-2099) is about 1.9 K. However there are other differences, for instance the average model resolution is higher in CMIP5 than in CMIP3, several of the CMIP5 models also have well resolved stratospheric dynamics (A. J. Charlton-Perez et al., Mean climate and variability of the stratosphere in the CMIP5 models, submitted to Journal of Geophysical Research, 2012) together with a consistent treatment of stratospheric ozone which is lacking in CMIP3 [Karpechko et al., 2008].

\footnotetext{
${ }^{1}$ Auxiliary materials are available in the HTML. doi:10.1029/ 2012GL052873.
} 
20CR IA spread
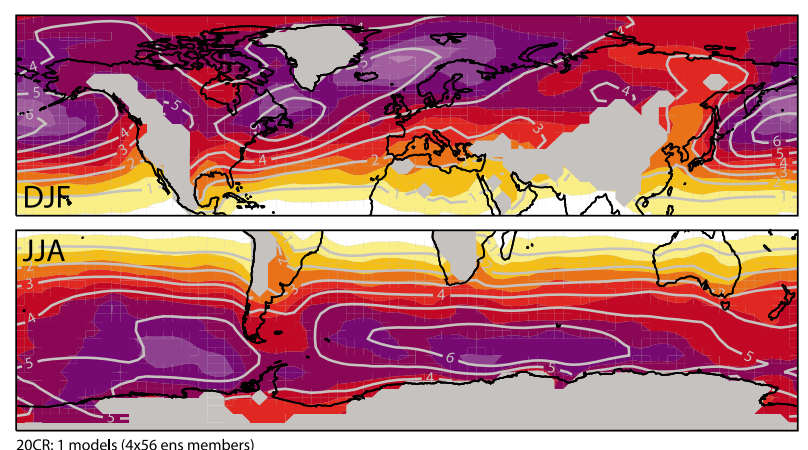

CMIP3/5 IA spread

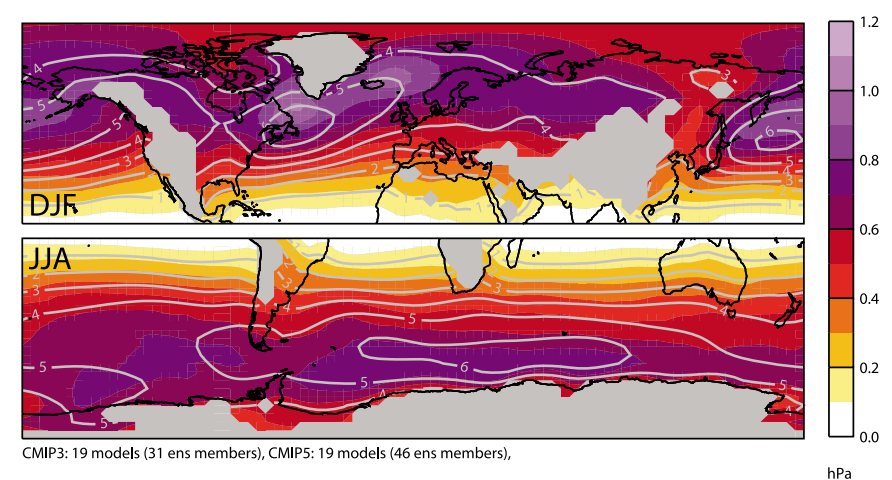

Figure 1. Wintertime MSLP storm tracks (contours; units: hPa) and their inter-annual standard deviations (shading) for (left) the 20CR dataset and (right) the combined CMIP3 and CMIP5 ensemble. In this and subsequent figures, the upper sub-panels show Northern Hemisphere DJF values and the lower sub-panels show Southern Hemisphere JJA values, both poleward of plus or minus 15 degrees respectively, and regions of land higher than $1 \mathrm{~km}$ have been masked.

[6] The measure of storm activity used in this study is the standard deviation of the 2-6 day bandpass filtered dailymean MSLP fields. This choice was adopted due to the limited availability of suitable data in the CMIP3 archive; it provides a simple assessment of synoptic scale activity using only daily mean MSLP data [Hoskins and Hodges, 2002; Chang, 2009]. The Lanczos filter with a 61-day convolution vector was used to filter the data, that length having a fairly clean frequency cut-off [Duchon, 1979]. The filter was applied to the whole time series, and then standard deviation values were calculated separately for each winter (December-February for the Northern Hemisphere and JuneAugust for the Southern Hemisphere) of each model run and of each ensemble member in the reanalysis.

[7] As a measure of the inter-annual variations of the storm tracks, the standard deviations of the seasonal storm track values were taken over each model run and each reanalysis ensemble member. As the model datasets are short compared to the reanalysis, the contribution from multi-decadal variations in the $20 \mathrm{CR}$ data was reduced by calculating the standard deviation values separately for four 30 year periods (1880-1909, 1910-1939, 1940-1969 and 1970-1999) and then taking the mean of the four values. Multiple runs of each scenario are available for several of the models. For these cases, the mean of the individual runs was first taken to give a single value for each model. Therefore, the multi-model means are averages over each run of each model, but with the data weighted by the inverse of the number of runs per model. Before combining, all of the data was regridded onto a common $4 \times 3$ degree grid using bi-linear interpolation.

\section{Storm Track Variability}

[8] Figure 1 shows the wintertime storm tracks and their inter-annual standard deviations for both the 20CR dataset and the multi-model mean of the combined set of CMIP3 and CMIP5 models, using the present-day scenarios (20C3M and $20 \mathrm{C}$ respectively). The figures serve to illustrate the typical values and spatial structures of these fields. In addition, they show that the multi-model mean storm tracks resemble well the large-scale features of the storm tracks in the reanalysis, albeit with a general tendency towards slightly smaller values (see Ulbrich et al. [2008] for a more complete comparison of the CMIP3 data with the NCEP-NCAR reanalysis dataset). The inter-annual standard deviation fields also have broad similarities, the main differences occurring over the northern North Atlantic, the eastern North Pacific and the eastern South Pacific, all of which exhibit larger values in the reanalysis than the multi-model mean. This may in part be due to inter-model variations in the spatial distribution of the inter-annual standard deviation. Since the interannual variability is of a similar magnitude in the models and reanalysis, each model's own variability has been used to compare with the magnitude of the responses in the analysis presented here.

[9] The typical maxima of this measure of storm activity in each of the major storm track regions is around $6 \mathrm{hPa}$ in both the 20CR reanalysis and the multi-model mean, whereas the inter-annual standard deviation values in these regions ranges from $0.6-1.0 \mathrm{hPa}$. Therefore, as a rough guide, typical year-to-year variations in this measure of the extra tropical storm tracks are of the order of $10-20 \%$ of the mean in the main storm track regions.

\section{Magnitude of the Climate Change Response}

[10] Figure 2 (top) shows the multi-model mean storm track responses separately for the CMIP3 and CMIP5 ensembles. Both ensembles exhibit an increase in storm activity over the Southern Ocean and a lesser, but not insignificant, decrease over much of the subtropical Pacific Ocean. The rest of the Northern Hemisphere also has qualitatively similar responses in the two ensembles, with increases over the midlatitude ocean basins, and decreases over most of the Arctic and North America regions. It is of note that with this measure of storm activity there is little sign of a poleward shift of the wintertime storm tracks, which is in contrast to other studies using different storm track diagnostics [Bengtsson and Hodges, 2006; Catto et al., 2011].

[11] Generally the CMIP3 responses are larger than the CMIP5 responses, consistent with the larger global mean temperature response discussed above. However, the storm track decreases over parts of the Arctic are weaker in the CMIP3 multi-model mean than in the CMIP5 multi-model mean. As an indication of the significance of this difference, 
CMIP3 Mean response: SRESA1B-20C3M
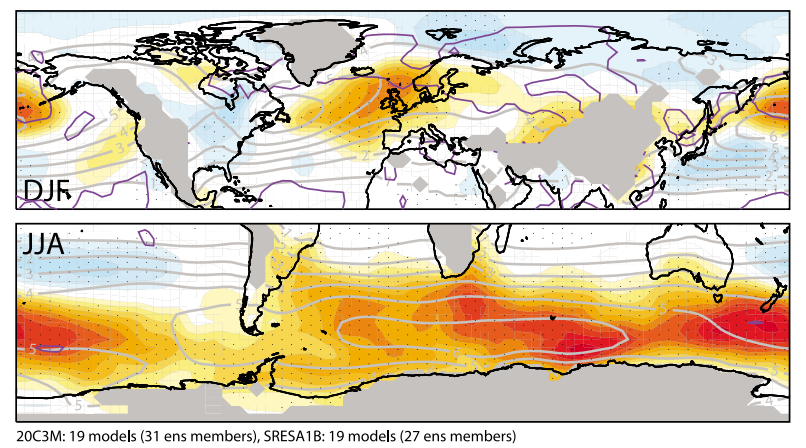

CMIP3 Consensus: SRESA1B-20C3M
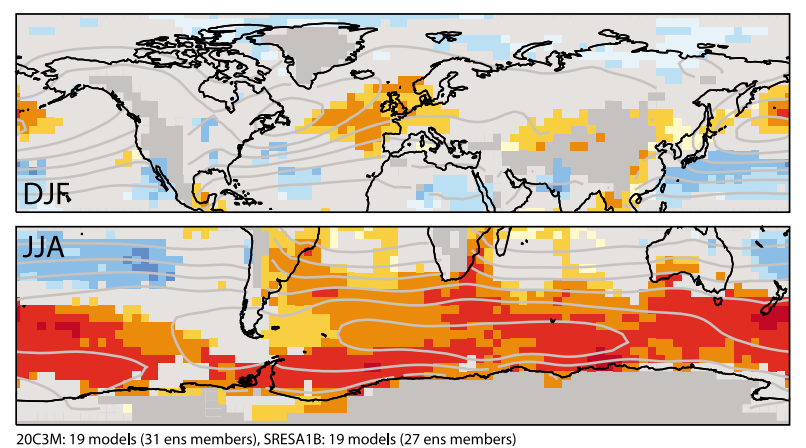

CMIP5 Mean response: RCP45-20C

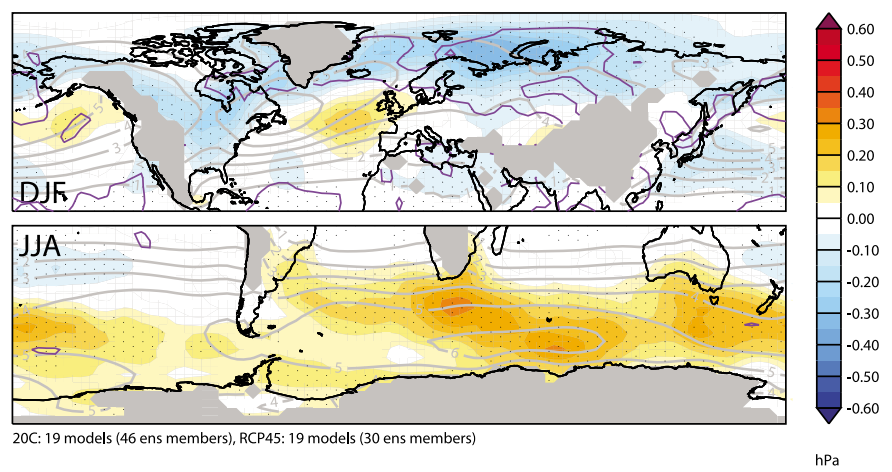

CMIP5 Consensus: RCP45-20C

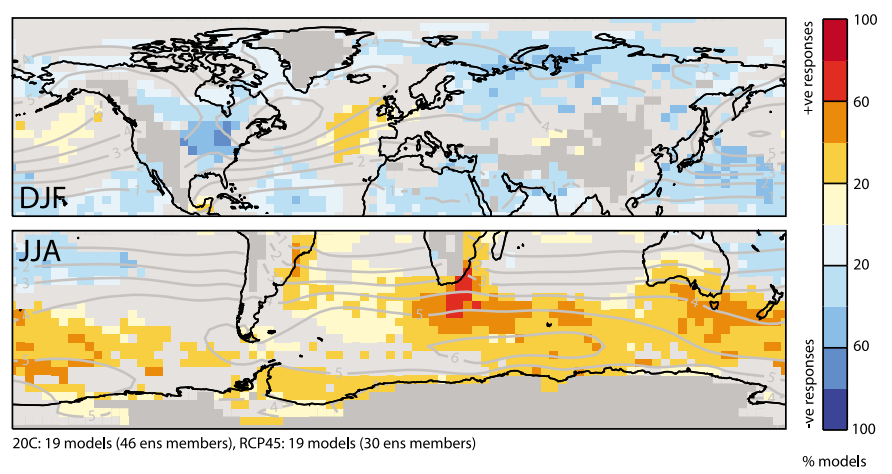

Figure 2. Multi-model mean MSLP storm tracks (gray contours; units: hPa) and (top) the global warming responses (shading), and (bottom) the percentage of models which have responses exceeding half of their inter-annual standard deviations. (left) CMIP3 data using the SRESA1B experiment and (right) CMIP5 data using the RCP4.5 experiment. In the upper panels stippling indicates responses that are different from zero at the $95 \%$ level according to a t-test based on the inter-model spread, whilst the single purple contour indicates locations where the scaled responses (see text) of the two ensembles differ from each other, again at the 95\% level.In the lower panels red and blue shading indicates that the responses are positive and negative respectively, and grid points where fewer than $70 \%$ of the models agree on the sign of the response are masked light gray.

relative to the ensemble spreads, a t-test has been performed comparing the CMIP3 responses with 1.5 times the CMIP5 responses. The factor of 1.5 is the ratio of the global mean temperature responses of the two ensembles and is used to crudely take account of the different emissions scenarios in the two experiments. The purple contour in Figure 2 shows where these values are different at the $95 \%$ level. The main regions outside of the tropics where the differences are not insignificant are confined to the sub-polar regions, in particular the ice-edge regions of both the Atlantic and Pacific oceans.

[12] It can be seen from comparing Figure 2 (top) with Figure 1 that the wintertime multi-model mean storm track response in both ensembles is everywhere smaller than the value of the inter-annual standard deviation. Throughout the Northern Hemisphere the response values are in fact less than half of the inter-annual standard deviation values, and are therefore small according to our criteria set out in the Introduction. But how consistent is this result across the individual models in the ensembles? To address this question Figure 2 (bottom) shows a measure of the consensus between the models. The plots show the percentage of models at each location that have large responses according to the criteria, that is, that have responses exceeding $50 \%$ of the inter-annual standard deviation. The CMIP3 ensemble has over $40 \%$ of models with large positive responses in large areas of the Southern Ocean, peaking at over $80 \%$ of models to the south of New Zealand, and also over $40 \%$ of models with large positive responses in small regions of the North Atlantic and Pacific oceans. The CMIP5 ensemble also has a number of models with large positive responses in the Southern Ocean, albeit a smaller overall percentage than CMIP3 consistent with the smaller global mean temperature changes; however in the Northern Hemisphere ocean basins only a few of the CMIP5 models exhibit large positive responses whereas up to $40 \%$ of models exhibit large negative responses over parts of the Arctic and North America. These differences are spatially similar to the differences in the multi-model mean patterns discussed above.

[13] These results rely on the assumption that the available datasets are sufficiently long to provide accurate estimates of the climate change responses of the individual models. Confidence intervals on the values shown in Figure 2 have been estimated using a random-sampling technique, the details and results of which are presented in the auxiliary material. Typical values shown there suggest that in the main storm track regions $90 \%$ confidence intervals are of the order $\pm 10 \%$.

[14] In order to illustrate the results in more detail, Figure 3 shows regional averages of the range of model 

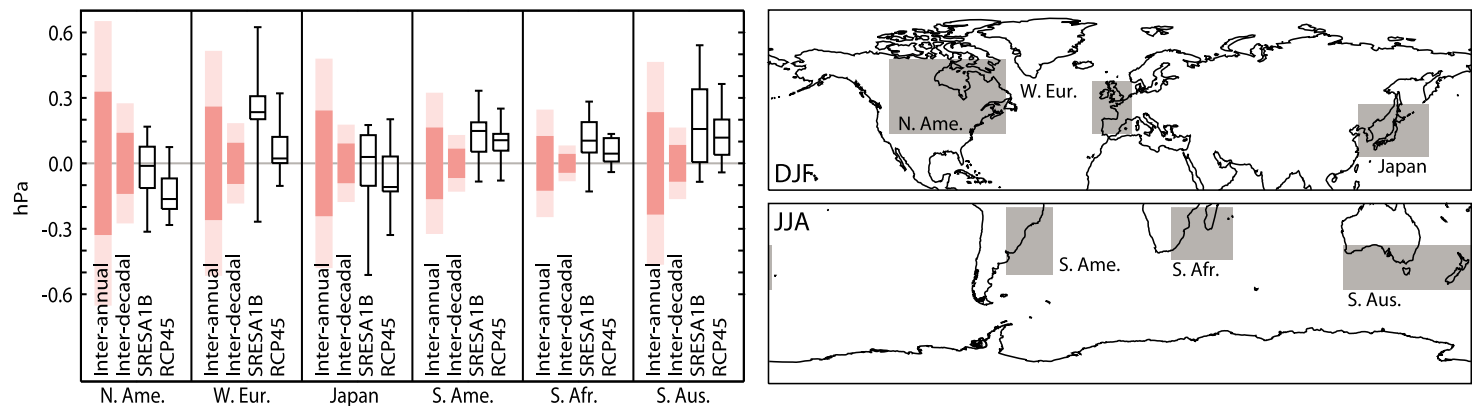

Figure 3. Regional summary of storm track variability and change (left) and a definition of the six regions used (right): The four bars plotted for each region are (from left to right): plus and minus the area-averaged inter-annual and inter-decadal standard deviations from the 20CR dataset, with the darker shading indicating half of the standard deviation values, the range of area-averaged response values in the CMIP3 SRESA1B experiments, and the range of area-averaged response values in the CMIP5 RCP4.5 experiments. The 'box and whisker' symbols indicate the median, the inter-quartile range and the extreme values in each case.

responses for each ensemble, as well as measures of the inter-annual and inter-decadal variability in the $20 \mathrm{CR}$ data. It is of note that the vast majority of the area with strong storm track responses is not over land. However, given the potential for societal impacts, the regions used here (illustrated in Figure 3, right) represent those areas of storm track responses that are near to and over land masses. They cover parts of Eastern North America, Western Europe, Japan, Eastern South America, Eastern South Africa and Southern Australasia. The inter-decadal standard deviation of the 20CR data is calculated separately for each of the 20CR ensemble members as the standard deviation between the time mean storm track of each consecutive ten year period, and then the ensemble mean taken. Typically, the interdecadal standard deviation values are just under half of the inter-annual standard deviation values.

[15] The left hand panel shows that, when averaged over the areas considered, the inter-model spread in the CMIP5 RCP4.5 responses is smaller than that of the CMIP3 SRESA1B responses. In each region considered there are models in each ensemble which have area-averaged responses of each sign. Consistent with the discussion above, there is more consistency between the two ensembles in the Southern Hemisphere regions, where typically the median responses are of a similar size to the inter-decadal spread values. In the Northern Hemisphere regions, whilst the CMIP5 models do lie almost entirely within the range of the CMIP3 models, the median values of the CMIP5 models fall outside of the inter-quartile range of the CMIP3 models.

\section{Discussion}

[16] This study has analyzed the changes of the wintertime bandpass filtered MSLP variance storm tracks in both the CMIP3 and CMIP5 multi-model ensembles using the 'middle-of-the-road' scenarios. Particular attention has been given to the magnitude of the responses relative to typical values of year-to-year variability. There are two main conclusions; the first is that the multi-model mean wintertime storm track responses in the CMIP3 and CMIP5 ensembles are largely in agreement, when scaled by the ensemble mean global temperature responses, although there are some significant differences in the sub-polar Northern Hemisphere, and the second is that the storm track responses of individual models are typically of the order of inter-decadal variations, and locally as large as inter-annual variations.

[17] In more detail, the multi-model mean response patterns of the two ensembles show strong similarities in the Southern Hemisphere, both in spatial structure and magnitude, but in the Northern Hemisphere there are differences with the CMIP5 multi-model mean response being more negative in the ice-edge regions of the Arctic than the CMIP3 multi-model mean response. The reasons for the differences are not investigated here, but some possible candidates include differences in the representation of the present-day storm tracks (ensemble means shown in Figure 2; see G. Zappa et al. (A multi-model perspective on the response of North Atlantic and Mediterranean cyclones to climate change, manuscript in preparation, 2012) for a more detailed comparison), changes in the resolution of the models, particularly in the stratosphere (Charlton-Perez et al., submitted manuscript, 2012), and also differences in the response of Arctic sea ice to climate change.

[18] Information on the distribution of the model responses is inferred by counting those models which locally exhibit large storm track responses, and it is shown that there are regions of the Northern Hemisphere where the responses of up to $40 \%$ of the models exceed half of the inter-annual variability, and for the Southern Hemisphere there are regions where up to $60 \%$ of the model responses exceed half of the inter-annual variability. In addition, there are regions where despite the multi-model mean response being small several individual models exhibit large responses. Reducing model uncertainty would therefore lead to improved confidence in the projected impact of storm track change. One limitation of the study is that the available datasets are not sufficiently long to provide precise estimates of the climate change responses of each model and as such confidence intervals for the number of models with large responses have also been derived in the auxiliary material, and found to be of the order $\pm 10 \%$. Our method assumes that each model's own mean storm track response is the best estimate of its true response, despite the sampling noise, and that the error range on this estimate is symmetric and proportional to the interannual standard deviation. A more sophisticated statistical model could be envisaged whereby the error bar for each model's response could be informed by information from the entire ensemble, thereby taking account of variations on time 
scales longer than the periods used (see P. G. Sansom et al., A statistical framework for interpreting climate change projections from multi-model ensembles, manuscript in preparation, 2012).

[19] Comparing the responses of atmospheric variables to typical values of present day variability is a natural way of interpreting the magnitude of changes. This study has only considered a single scenario from each of the CMIP3 and CMIP5 ensembles. One avenue for future work is to perform a full assessment of scenario uncertainty within each model ensemble. In addition, the improvement in data available between CMIP3 and CMIP5 will allow for a much more detailed study into the changes of the storm tracks using more sophisticated cyclone-tracking diagnostics (e.g., Zappa et al., manuscript in preparation, 2012).

[20] Acknowledgments. All authors thank the two anonymous reviewers for their assistance in evaluating this paper. BJH and GZ were supported the Natural Environment Research Council's project 'Testing and Evaluating Model Predictions of European Storms' (TEMPEST) during the course of this work. Support for the Twentieth Century Reanalysis Project dataset is provided by the U.S. Department of Energy, Office of Science Innovative and Novel Computational Impact on Theory and Experiment (DOE INCITE) program, and Office of Biological and Environmental Research (BER), and by the National Oceanic and Atmospheric Administration Climate Program Office. We also acknowledge the World Climate Research Programme's Working Group on Coupled Modelling, which is responsible for CMIP, and we thank the climate modeling groups for producing and making available their model output. For CMIP the U.S. Department of Energy's Program for Climate Model Diagnosis and Intercomparison provides coordinating support and led development of software infrastructure in partnership with the Global Organization for Earth System Science Portals.

[21] The Editor thanks the two anonymous reviewers for assisting in the evaluation of this paper.

\section{References}

Alexandersson, H., T. Schmith, K. Iden, and H. Tuomenvirta (1998), Longterm trend variations of the storm climate over NW Europe, Global Atmos. Ocean Syst., 6, 97-120.

Bengtsson, L., and K. I. Hodges (2006), Storm tracks and climate change, J. Clim., 19, 3518-3543.

Catto, J. L., L. C. Shaffrey, and K. I. Hodges (2011), Northern Hemisphere extratropical cyclones in a warming climate in the HiGEM high resolution climate model, J. Clim., 24, 5336-5352.

Chang, E. K. M. (2009), Are band-pass variance statistics useful measures of storm track activity? Re-examining storm track variability associated with the NAO using multiple storm track measures, Clim. Dyn., 33, 277-296.

Compo, G., et al. (2011), The twentieth century reanalysis project, Q.J.R. Meteorol. Soc., 137, 1-28.
Cornes, R. C., and P. D. Jones (2011), An examination of storm activity in the northeast Atlantic region over the 1851-2003 period using the EMULATE gridded MSLP data series, J. Geophys. Res., 116, D16110, doi:10.1029/2011JD016007.

Dailey, P., M. Huddleston, S. Brown, and D. Fasking (2009), The financial risks of climate change, technical report, AIR Worldwide Corp. and Met Off., Exeter, U. K.

Donat, M. G., D. Renggli, S. Wild, L. V. Alexander, G. C. Leckebusch, and U. Ulbrich (2011), Reanalysis suggests long-term upward trends in European storminess since 1871, Geophys. Res. Lett., 38, L14703, doi:10.1029/2011GL047995.

Duchon, C. (1979), Lanczos filtering in one and two dimensions, J. Appl. Meteorol., 18, 1016-1022.

Hawkins, E., and R. Sutton (2012), Time of emergence of climate signals, Geophys. Res. Lett., 39, L01702, doi:10.1029/2011GL050087.

Hoskins, B. J., and K. I. Hodges (2002), New perspectives on the Northern Hemisphere winter storm tracks, J. Atmos. Sci., 59, 1041-1061.

Karpechko, A. Y., N. P. Gillett, G. J. Marshall, and A. A. Scaife (2008), Stratospheric influence on circulation changes in the Southern Hemisphere troposphere in coupled climate models, Geophys. Res. Lett., 35, L20806, doi:10.1029/2008GL035354.

Mahlstein, I., R. Knutti, S. Solomon, and R. W. Portmann (2011), Early onset of significant local warming in low latitude countries, Environ. Res. Lett., 6, 034009.

Mahlstein, I., R. W. Portmann, J. S. Daniel, S. Solomon, and R. Knutti (2012), Perceptible changes in regional precipitation in a future climate, Geophys. Res. Lett., 39, L05701, doi:10.1029/2011GL050738.

Meehl, G., C. Covey, T. Delworth, M. Latif, B. McAvaney, J. Mitchell, R. Stouffer, and K. Taylor (2007), The WCRP CMIP3 multi-model dataset: A new era in climate change research, Bull. Am. Meteorol. Soc., $88,1383-1394$.

Pinto, J. G., E. L. Fröhlich, G. C. Leckebusch, and U. Ulbrich (2007), Changing European storm loss potentials under modified climate conditions according to ensemble simulations of the ECHAM5/MPI-OM1 GCM, Nat. Hazards Earth Syst. Sci., 7, 165-175.

Schwierz, C., P. Köllner-Heck, E. Zenklusen Mutter, D. N. Bresch, P. L. Vidale, M. Wild, and C. Schär (2010), Modelling European winter wind storm losses in current and future climate, Clim. Change, 101, 485-514.

Taylor, K. E., R. J. Stouffer, and G. A. Meehl (2011), An overview of CMIP5 and the experiment design, Bull. Am. Meteorol. Soc., 93, 485-498.

Ulbrich, U., J. Pinto, H. Kupfer, G. Leckebusch, T. Spangehl, and M. Reyers (2008), Changing Northern Hemisphere storm tracks in an ensemble of IPCC climate change simulations, J. Clim., 21, 1669-1679.

Ulbrich, U., G. C. Leckebusch, and J. G. Pinto (2009), Extra-tropical cyclones in the present and future climate: A review, Theor. Appl. Climatol, 96, 117-131.

Wang, X. L., F. W. Zwiers, V. R. Swail, and Y. Feng (2009), Trends and variability of storminess in the northeast Atlantic region, 1874-2007, Clim. Dyn., 33, 1179-1195.

Yin, J. H. (2005), A consistent poleward shift of the storm tracks in simulations of 21 st century climate, Geophys. Res. Lett., 32, L18701, doi:10.1029/2005GL023684. 